\title{
Situs inversus totalis: revisión de tema con aproximación a la Genética y reporte de casos
}

\author{
Vicente de Jesús Aljure Reales ${ }^{a}$, Gloria Camila Álvarez Gallego ${ }^{\mathrm{b}, \mathrm{c}}$, \\ Nasly Consuelo Ávila Espitia ${ }^{\mathrm{b}, \mathrm{c}, *}$, Alexandra Arrieta Coley ${ }^{\mathrm{b}, \mathrm{c}}$ \\ y Orlando Germany Ángel Suárez ${ }^{\mathrm{b}, \mathrm{d}}$
}

\author{
a Universidad Nacional de Colombia, Bogotá, Colombia \\ b Grupo de investigación clínica, Salud San Rafael, Hospital San Rafael, Tunja, Colombia \\ c Facultad de Medicina, Universidad Pedagógica y Tecnológica de Colombia, Tunja, Colombia \\ ¿ Grupo de investigación trasplante de órganos sólidos y tejidos, Departamento de cirugía, Universidad Nacional de Colombia, \\ Bogotá, Colombia
}

Recibido el 1 de diciembre de 2015; aceptado el 9 de junio de 2016

Disponible en Internet el 10 de diciembre de 2016

\author{
PALABRAS CLAVE \\ Situs inversus; \\ Anomalías \\ congénitas; \\ Síndrome de \\ Kartagener; \\ Genética
}

\begin{abstract}
Resumen
Objetivo: Efectuar una revisión actualizada del situs inversus totalis y presentar casos clínicos. Métodos: Se hizo una revisión de las principales bases de datos y se incluyeron los estudios más relevantes correspondientes a 20 años previos, en español e inglés, en todos los grupos etáreos y étnicos, incluidos: metaanálisis, revisiones sistemáticas, ensayos clínicos, estudios de cohorte y casos clínicos relevantes. Se consultaron bases de datos como EBSCO, Medline, PubMed y SciELO entre otras, para obtener información actualizada. Los términos de búsqueda fueron situs inversus, totalis.

Resultados: El situs inversus totalis es una variante anatómica poco frecuente que involucra estructuras toraco-abdominales, hace parte de otras variantes de situs, tiene un patrón de herencia poligénico, sin una relación directa establecida; es además una entidad asintomática, reconocida desde tiempos antiguos.

Conclusiones: Aunque es una patología de baja incidencia en la población, y un hallazgo incidental, es importante reconocerla como una variante anatómica que puede cursar con patologías concomitantes. A pesar de que existen estudios, se requieren otros con alta significancia estadística. Se encuentra relación de los casos con la información de la literatura que concluyen un estudio acertado.

(C) 2016 Sociedad Colombiana de Cardiología y Cirugía Cardiovascular. Publicado por Elsevier España, S.L.U. Este es un artículo Open Access bajo la licencia CC BY-NC-ND (http:// creativecommons.org/licenses/by-nc-nd/4.0/).
\end{abstract}

\footnotetext{
* Autor para correspondencia.

Correo electrónico: naslyc0512@gmail.com (N.C. Ávila Espitia).
} 


\section{KEYWORDS}

Situs inversus; Congenital anomalies; Kartagener syndrome; Genetics

\section{Situs inversus totalis, topic review approach to Genetics and case report}

\begin{abstract}
Objective: To conduct an updated review of situs inversus totalis and present clinical cases. Methods: A review of the main databases was conducted, and the most relevant studies over the last 20 years were included, both in Spanish and English, in all age and ethnic groups, including: meta-analysis, systematic reviews, clinical trials, cohort studies and relevant clinical cases. Databases such as EBSCO, Medline, PubMed and SciELO were consulted among others to obtain updated information. Search terms were "situs inversus", "totalis".

Results: Situs inversus totalis is a rare anatomical variant that involves thoracoabdominal structures, takes part in other situs variants, has a polygenic inheritance pattern, without a direct established relationship; is also an asymptomatic entity, recognised since ancient times.

Conclusion: Despite being a condition with a low incidence in the population and having an incidental finding, it is important to recognise it as an anatomical variant that can coexist with concomitant diseases. Although studies exist, more are required with a higher statistical significance. A relationship is found between the cases with the information found in the literature, which leads to a strong research $</$ org $>$.

(c) 2016 Sociedad Colombiana de Cardiología y Cirugía Cardiovascular. Published by Elsevier España, S.L.U. This is an open access article under the CC BY-NC-ND license (http:// creativecommons.org/licenses/by-nc-nd/4.0/).
\end{abstract}

\section{Introducción}

El dolor abdominal es uno de los principales motivos de consulta a urgencias ${ }^{1}$, de ahí que se deban plantear múltiples diagnósticos diferenciales para llegar a uno definitivo. La semiología puede ser confusa como en pacientes con situs inversus totalis (SIT), una variante anatómica de baja incidencia.

En este documento se referencian dos casos clínicos captados en el servicio de urgencias de la institución, que tienen en común sexo, edad fértil y dolor abdominal como motivo de consulta. El examen físico de ingreso puede ser confuso ya que los lugares de referencia para el dolor usualmente están invertidos; por ejemplo, se puede confundir el dolor de la colecistitis con el dolor causado por distensión gástrica, así como el de la apendicitis aguda con la diverticulitis. Sin embargo, otro de los problemas evidenciados radica en el examinador, al no dar la suficiente importancia a un examen físico detallado, pasando por alto signos claves para diagnosticar SIT, como cambios en los focos de auscultación cardiaca. Como se mencionaba, los signos se verán alterados en esta variante anatómica. Los hallazgos en las imágenes diagnósticas y la pericia del médico tratante serán decisivos en el diagnóstico ${ }^{2,3}$ (figs. 1 y 2).

Existen algunas patologías asociadas en estos casos, como el síndrome de Kartagener a nivel respiratorio, algunas neoplasias de vísceras abdominales y enfermedades del corazón como malformaciones cardiacas en recién nacidos.

Se efectuó una revisión de la literatura actual respecto al tema y se encontraron aspectos comunes con los casos analizados; pese a la escasa información recolectada se incluyeron recomendaciones de metaanálisis, revisiones sistemáticas y ensayos clínicos.

\section{Materiales y métodos}

Se consultaron bases de datos como EBSCO Medline, PubMed y SciELO, y se extrajeron los estudios más relevantes correspondientes a los 20 años previos a la redacción de este material científico, con el fin de proporcionar al lector un documento en el que se expone el SIT de manera precisa y se involucran los aspectos más sobresalientes de esta variante anatómica. Se tuvieron en cuenta metaanálisis, revisiones sistemáticas, ensayos clínicos, estudios de cohorte y casos clínicos relevantes. Se emplearon los términos MESH: Situs Inversus + totalis. Se tuvieron en cuenta estudios en inglés, español y portugués, en todos los grupos etáreos y etnias.

\section{Reporte de casos}

\section{Caso 1}

Paciente femenina de 21 años, primigestante en puerperio mediato, quien acudió al servicio de urgencias de la institución el día 12 de mayo de 2015 por cuadro clínico de 3 días de evolución consistente en cefalea frontal de intensidad moderada, picos febriles y diaforesis. El cuadro se agudizó con dolor abdominal tipo cólico generalizado de predominio en epigastrio, de gran intensidad, acompañado de episodios diarreicos que asoció a ingesta alimentaria. Durante el examen físico se halló: TA: $100 / 54 \mathrm{~mm} \mathrm{Hg}, \mathrm{FC}$ : 120, FR: $18, \mathrm{~T}: 37,9^{\circ} \mathrm{C}$ y palidez mucocutánea generalizada. Abdomen: Bloomberg dudoso, Rovsing negativo, sin signos de irritación peritoneal. PCR: 3,3. CH: normal, PO: normal. Debido a la persistencia del cuadro clínico se sospechó apendicitis, por lo cual se hizo ecografía abdominal que mostró bazo localizado a la derecha, ápex cardiaco a la derecha, no hígado intraperitoneal y útero aumentado de tamaño por puerperio mediato. Se diagnosticó SIT; no se evidenciaron patologías intraabdominales. Puesto que los hallazgos ecocardiográficos reportados no fueron concluyentes para orientar un diagnóstico certero, se realizó tomografía computarizada (TC) abdomino-pélvica, la cual confirmó SIT, útero aumentado de volumen en relación al puerperio mediato y engrosamiento difuso de la pared del colon descendente y transverso (fig. 1). 


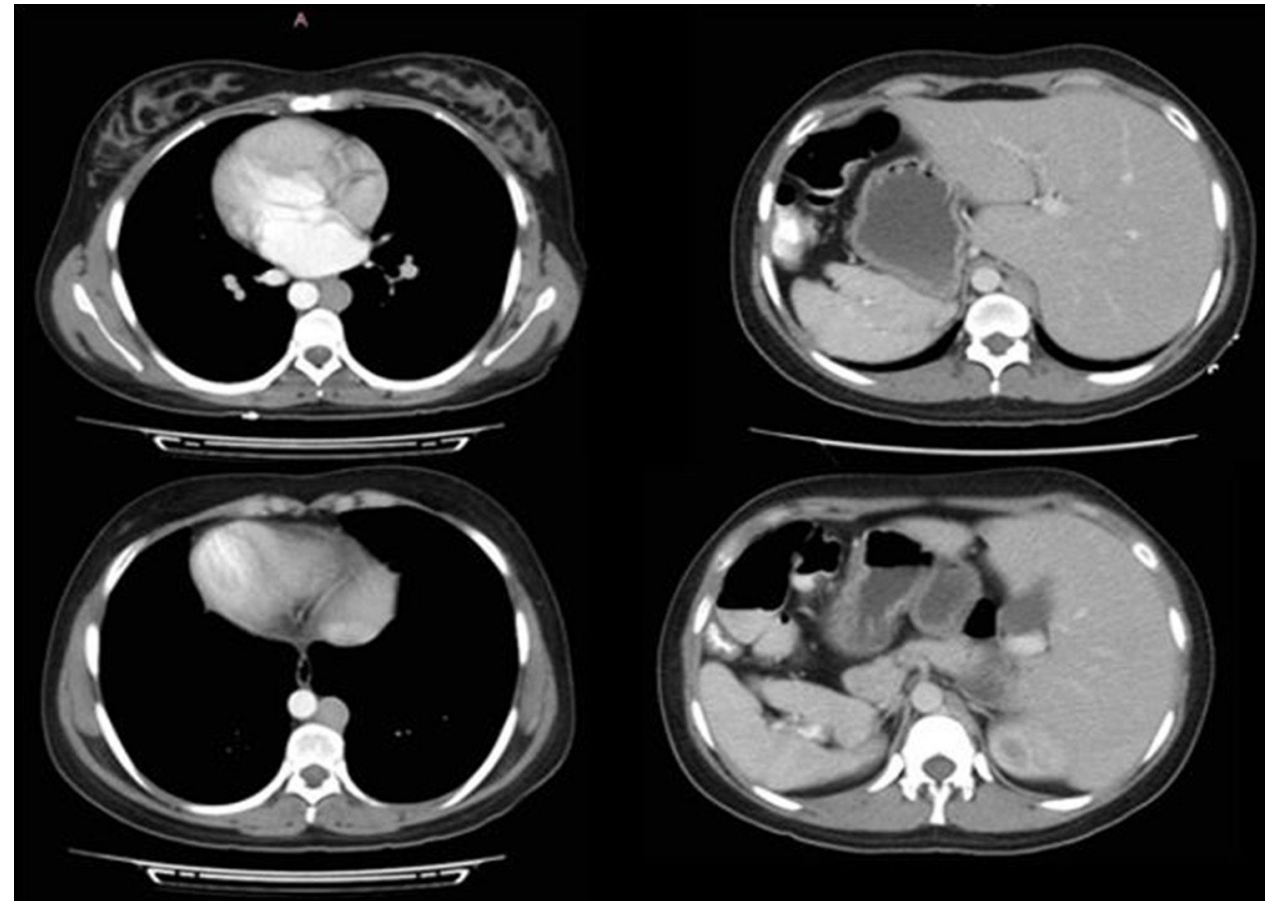

Figura 1 Situs inversus caso 1. Se evidencia trasposicion del ápex cardiaco (superior izquierda), grandes vasos (inferior izquierda), hígado y bazo (superior e inferior derecha).

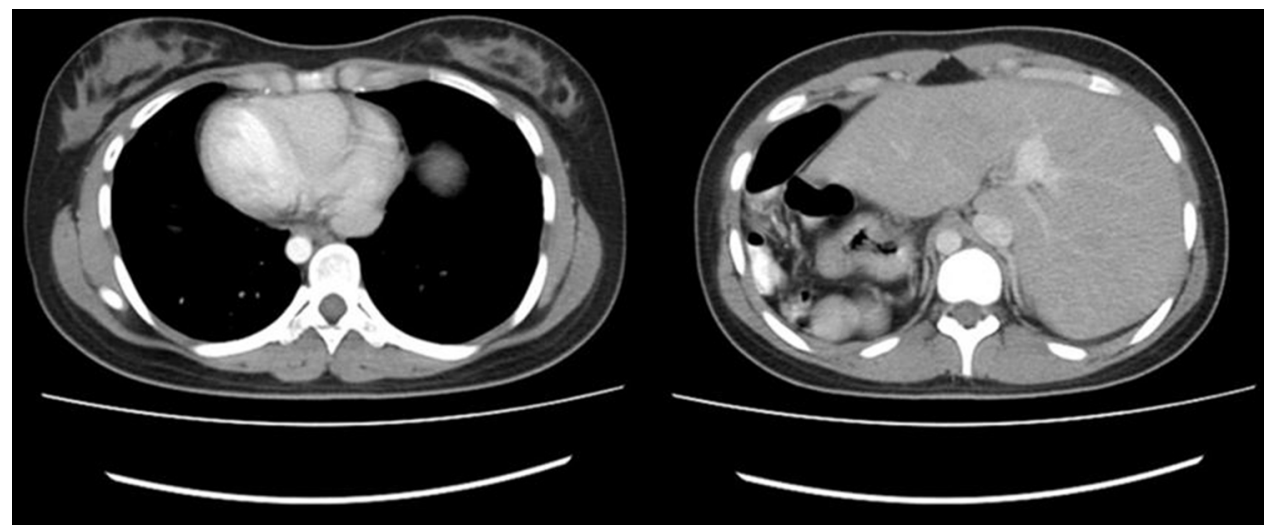

Figura 2 Trasposición de grandes vasos y ápex cardíaco (izquierda). Transposición de hígado y vesícula biliar (derecha).

\section{Caso 2}

Paciente femenina de 19 años de edad, quien acudió al servicio de urgencias de la institución por presentar cuadro clínico de $24 \mathrm{~h}$ de evolución consistente en dolor abdominal localizado en epigastrio e hipogastrio, persistente, que aumentaba en intensidad; en la consulta presentó intensidad 8/10 en la escala visual análoga. Asociado al cuadro tuvo tres episodios eméticos de contenido alimentario y 8 episodios diarreicos. En el examen físico de ingreso se encontró: TA: 185/83 mm Hg, FC: 112, FR: 16. Abdomen: blando, dolor generalizado a la palpación que predominaba en epigastrio y fosa ilíaca derecha, Bloomberg y Murphy negativos. Fosfatasa alcalina: 84 , amilasa sérica: 102 , PCR: 135 , leucocitos: 14.000, neutrófilos: 70\%, linfocitos: 19\%, monocitos: $9 \%$. La impresión diagnóstica del cuadro fue colestasis vs. apendicitis. Para su confirmación se realizó ecografía abdominal, que reveló ápex cardiaco a la derecha, vísceras abdominales en localización inversa, hígado a la izquierda y bazo a la derecha. Se diagnosticó SIT y se descartó patología en las dos vísceras mencionadas. Estos hallazgos se confirmaron mediante TC (fig. 2).

\section{Resultados}

El SIT hace referencia a una variante anatómica infrecuente de los órganos abdominales y torácicos, de herencia autosómica recesiva, caracterizada por la transposición de izquierda-derecha de los mismos respecto al plano sagital $^{3-6}$. Se debe a una perturbación durante la tercera semana del desarrollo embriológico que corresponde a la etapa de gastrulación en la que se establecen los ejes derecha-izquierda del embrión. Se cree que en esta 
modificación están implicados el factor de crecimiento fibroblástico 8 , el gen Lefty1 y PITX2 $2^{4,7,8}$.

Ocurre aproximadamente con una frecuencia de $1 / 10.000$ en la población general, en una relación mujer-hombre 1:1,5, sin predilección racial ${ }^{2,9,10}$.

Se ha observado en los animales desde los tiempos de Aristóteles, quien fue el primero en registrarlo y además lo consideró como una visita de los dioses; así mismo, la dextrocardia fue dibujada por Leonardo da Vinci (14521519), pero fue publicada científicamente por primera vez por Marco Severino en 1643. En humanos fue descrito inicialmente por Fabricius quien publicó este hallazgo en el siglo $\mathrm{XVII}^{11}$. En cuanto a su diagnóstico, el examen físico fue destacado como ayuda de gran significancia, principalmente con los métodos exploratorios de auscultación y percusión, descritos por Kuchemeister en $1864^{12}$. La evolución en el diagnóstico de esta anomalía siguió avanzando con la utilización de imágenes por Vehemeyer, en 1867, quien empleó inicialmente la radiografía simple para su descripción ${ }^{10}$. Un siglo después, Baillie describió la inversión completa en imagen en espejo de los órganos toraco-abdominales en situs inversus $^{13,14}$.

\section{Clasificación}

Un complejo grupo de anormalidades viscerales y vasculares congénitas son características de las anormalidades del SIT (disposición de los órganos torácicos e intraabdominales). El situs solitus se describe como la disposición normal de órganos corporales, ápex cardiaco, aorta, pulmón bilobulado, estómago y bazo a la izquierda del eje axial, y vena cava inferior, hígado junto con la vesícula y pulmón trilobulado a la derecha de dicho eje $\mathrm{e}^{15}$.

El situs ambiguous el cual se presenta en 1:10.000 a $1: 20.000$, se refiere a la modificación de la conformación anatómica normal, instaurándose isomerismo derecho o izquierdo, en el que se presenta la subdivisión en situs ambiguous con poliesplenia, situs ambiguous con asplenia y síndrome de Ivemark. El situs ambiguous con asplenia tiene mayor prevalencia en hombres, hay duplicación de las vísceras del lado derecho y se ubican en el lado opuesto, presentan típicamente síndrome de dificultad respiratoria del adulto y anomalías cardiacas severas. En contraste, el situs ambiguous con poliesplenia tiene mayor prevalencia en mujeres y las estructuras que se disponen del lado izquierdo del eje axial se encuentran duplicadas; así mismo, los pacientes con esta variación presentan patología cardiaca congénita en menor proporción ${ }^{15}$.

Finalmente, el situs inversus es la imagen en espejo del situs solitus, el cual presenta subdivisión en situs inversus totalis, que es la forma más usual, caracterizada por la ubicación en espejo de los órganos intraabdominales y torácicos incluyendo el corazón; el ápex cardiaco, el bazo, el estómago, el yeyuno, el colon descendente y la aorta se encuentran localizadas como estructuras corporales derechas. El pulmón derecho es bilobulado, con bronquio hiparterial. La vena cava inferior, el hígado junto con la vesícula, el ligamento de Treitz, el íleon y el colon ascendente son estructuras localizadas en la región izquierda del cuerpo. Por último, el situs inversus parcial es menos habitual, con una prevalencia de 1:22.000 nacidos ${ }^{15}$, y principalmente se encuentra la imagen en espejo de los órganos intraabdominales y torácicos, pero el corazón en disposición normal ${ }^{9}$.

\section{Genética aplicada}

Los elementos patogénicos del SIT no han sido bien establecidos, aunque algunos patrones genéticos están involucrados, incluyendo un gen autosómico recesivo situado en el brazo largo del cromosoma 14 y supresiones que afectan a los cromosomas 7 u $8^{14,16}$. Recientemente, se ejecutaron importantes avances en el entendimiento de las posibles vías moleculares involucradas en este proceso, que sugieren que la mutación que afecta a CCDC11 y a genes DNAH11, está implicada en defectos de lateralidad autosómicos recesivos de fenotipo variado, que resulta en la mutación en CCDC11 y da como resultado una proteína anormalmente pequeña en los fibroblastos cutáneos del paciente ${ }^{17-19}$. Además, se ha demostrado que las mutaciones en el gen de la familia TGF- $\beta$ y en el factor de transcripción HNF-3 $\beta$ tienen un papel factible en el proceso $^{18}$.

ZIC3 es parte de la familia de genes ZIC. El gen codifica un factor de transcripción dedo de zinc fi y su papel en el desarrollo de la asimetría izquierda-derecha sigue siendo en gran parte desconocido, pese a que los modelos de ratones sugieren que ZIC3 puede interactuar con la vía de señalización nodal; también puede tener un rol en la regulación directa del desarrollo cardíaco y en el mantenimiento de la pluripotencialidad en células madre embrionarias. El SIT se ha reportado en la mutación de ZIC3 en mujeres heterocigotas y se cree que la mayoría de los casos reportados en la literatura surgen de defectos en la función ciliar ${ }^{20}$.

Existe una variación fenotípica marcada en los varones con heterotaxia ligada al $x$ asociada con mutaciones en ZIC3. Aunque no cabe descartar la presencia de la mutación en ZIC3 asociada al SIT, en la literatura, se presenta el primer caso de situs inversus asociado a una mutación ZIC3 en un varón. Esto confirma la penetrancia incompleta del gen $^{21}$.

Se han asociado algunas mutaciones a enfermedad quística renal y situs inversus, en los genes INVS (nefronoptisis tipo 2), una en NPHP3 (nefronoptisis tipo 3), y otra en CEP290 (nefronoptisis tipo 6). Por otra parte, mutaciones en el gen PK2D se encuentran asociadas a la presentación de $\mathrm{SIT}^{22}$

La vía de señalización de Hedgehog $(\mathrm{Hg})$ es preponderante en el desarrollo embrionario y en la función de las células madre de los adultos. Irregularidades en esta vía causan defectos congénitos y cáncer. NBCCS es conocido por causar mutaciones en el PTCH1, el receptor de Hg. PTCH1 se localiza en los cilios primarios e interviene en los pasos clave para la transducción de la señal de Hg. Se ha sugerido que una disfunción ciliar a través de la desregulación de la vía $\mathrm{Hg}$, es la causa subyacente del situs inversus ${ }^{22}$.

\section{Comorbilidades asociadas}

El SIT no se considera una condición premaligna; no obstante, se han reportado múltiples malignidades gastrointestinales primarias sincrónicas y metacrónicas raras. Aún no 
se encuentra una fuerte asociación entre los genes que afectan el eje derecha-izquierda y la susceptibilidad al cáncer ${ }^{23}$.

Se han descrito comorbilidades con un 5 a un $10 \%$ de probabilidad de presentar malformaciones cardiovasculares como tetralogía de Fallot y trasposición de grandes vasos corregida ${ }^{3}$, además de estenosis pulmonar y defectos en el tabique auricular o ventricular asociados a la dextrocardia ${ }^{24}$. También se reportan comorbilidades respiratorias, principalmente disquinesia ciliar primaria, como síndrome de Kartagener, con alteración en la dineína, descrito por primera vez en 1933, característico por la tríada: SIT, bronquiectasias y sinusitis paranasal que aumentan la frecuencia de infecciones respiratorias ${ }^{25,26}$; es una enfermedad autosómica recesiva, se presenta en 17 a $25 \%$ de pacientes con SIT, de cuadro clínico muy diverso, que por tanto se diagnostica usualmente en estado avanzado cuando hay daño pulmonar extremo; solo la mitad de los individuos con esta afectación se manifiesta con $\mathrm{SIT}^{1,9,27,28}$. Adicionalmente, se encuentran anomalías intestinales y anormalidades viscerales, como atresia biliar ${ }^{29}$. Las cardiopatías congénitas se observan en solo 3 a $5 \%$ en SIT, generalmente con transposición de grandes vasos corregida; de estos pacientes, el $80 \%$ tiene un arco aórtico derecho. Esta transposición puede permanecer asintomática hasta la edad adulta, cuando aparecen insuficiencias y arritmias cardiacas que dañan el sistema morfológico del ventrículo derecho por presentar presiones elevadas ${ }^{30,31}$.

Cuando esta entidad coexiste con patologías abdominales como la colelitiasis, se requiere intervención quirúrgica para su tratamiento. El diagnóstico previo es fundamental, ya que esta condición genética hace obligatoria la modificación de la técnica quirúrgica, principalmente laparoscópica ${ }^{3,20}$.

En patologías cardiacas que requieran cateterismo, el cambio de posición de las estructuras cardiovasculares supone una dificultad adicional en el procedimiento; el posicionamiento del catéter es crucial, ya que pueden producirse complicaciones como desplazamientos del mismo, fallos de captura en el electrocardiograma en los cuales hay falla en la estimulación ventricular en pacientes con marcapasos ${ }^{32}$ o más graves como la perforación de la pared libre del ventrículo derecho con posterior taponamiento cardiaco, aumentándose así la mortalidad y la necesidad de una intervención quirúrgica de urgencia. Estos pacientes también pueden presentar una vena cava superior izquierda que modifica la anatomía normal. Su omisión puede lesionar estructuras adyacentes y causar complicaciones en procedimientos como la ablación del nódulo sinusal en el tratamiento de la fibrilación auricular ${ }^{33}$.

\section{Trasplante y situs inversus totalis}

El SIT es considerado una contraindicación absoluta en el ámbito de la donación de órganos desde 1988, ya que representa un riesgo altísimo para complicaciones, especialmente en trasplantes de hígado y corazón. Los principales inconvenientes se relacionan con la vasculatura e inervación visceral; para trasplante renal es una contraindicación relativa, ya que las intervenciones de este tipo en su mayoría han sido exitosas.

\section{Presentación}

Usualmente el SIT es un hallazgo incidental; los individuos con esta anomalía consultan al servicio médico por presentar patologías habituales en la práctica clínica que precisan imágenes diagnósticas, evidenciándose la inversión izquierda-derecha de los órganos toraco-abdominales con implicaciones clínicas y modificación del manejo quirúrgico como se mencionó anteriormente ${ }^{34}$.

\section{Diagnóstico}

Para definir el SIT se usa la radiografía de tórax simple, útil para evidenciar dextrocardia, la ultrasonografía, la tomografía axial computarizada (TAC) y la resonancia magnética para evaluar la situación de estructuras clave como: ápex cardiaco, aurículas, aorta, pulmones bilobulados y trilobulados, estómago, hígado, vesícula y finalmente el bazo ${ }^{1,9}$; la ultrasonografía ha mostrado sensibilidad y especificidad del 50 y del $90 \%$, respectivamente. Se reporta un caso de diagnóstico prenatal de SIT que evidencia la importancia del diagnóstico temprano, para la intervención en patologías congénitas asociadas ${ }^{35}$. Por su parte, la TAC tiene sensibilidad y especificidad del $99 \%, 36$.

Como se ha expuesto a lo largo de la revisión, la dextrocardia es una de las características clave para el diagnóstico del SIT. Por tanto, para la detección de esta patología es esencial el ecocardiograma transesofágico ${ }^{37}$. Para efectuar un diagnóstico completo en edades tempranas, el ecocardiograma transtorácico permite definir las relaciones entre las estructuras cardiacas y comprobar la existencia o no de cardiopatías estructurales $^{38}$.

\section{Pronóstico}

Pese a que la mayoría de individuos con SIT cursan con vida sana, aproximadamente 1 de cada 20 puede sufrir patologías cardíacas y aproximadamente 1 de cada 5 síndrome de Kartagener coexistente ${ }^{34}$.

Así mismo, se ha encontrado asociación entre la mutación o pérdida del gen CCDC11, encargado del arreglo de izquierda a derecha, y la expresión de algunos tipos de cáncer ${ }^{26,37}$, esto último, apoyado en que los pacientes con SIT pueden estar en alto riesgo de desarrollarlos debido a una deficiencia congénita en la función de $\mathrm{KIF}$, proteína intracelular necesaria para la ciliogénesis ${ }^{39}$. Además, se ha sugerido que la disfunción ciliar por la desregulación de la vía Hedgehog, puede ser la causa subyacente del $\mathrm{SIT}^{40}$.

Se han reportado diversos tipos de cáncer entre estos de estómago, colon, páncreas, tracto biliar, ampolla de Vater y riñón. Los carcinomas del tracto biliar son relativamente raros, representan menos del $1 \%$ de todos los cánceres; el adenocarcinoma de la vesícula biliar aporta el $4 \%$ y el colangiocarcinoma el $3 \%$ de los cánceres gastrointestinales ${ }^{40}$. Es necesario puntualizar que, aunque se postula la asociación de SIT con malignidad, las hipótesis aún no muestran resultados claros; por tanto, se requiere más investigación al respecto ${ }^{37}$. 


\section{Discusión}

La conformación anatómica de los órganos internos normales del ser humano se desarrolla a partir de la tercera semana de gestación, etapa del desarrollo embrionario en la que se define el eje izquierda-derecha el cual es susceptible a cambios, entre ellos, el SIT.

Los casos expuestos tienen en común el sexo femenino, lo cual no avala los hallazgos propuestos en la literatura mundial, donde se reporta una relación de género de 1,5: 1 hombre vs. mujer, respecto a la epidemiología mundial ${ }^{2,10}$.

El grupo etáreo de SIT dependerá de la epidemiología de patologías asociadas, como la apendicitis, que presenta mayor prevalencia en la infancia y adolescencia, así como enfermedades cardiacas en el adulto mayor ${ }^{2}$.

Aunque los elementos genéticos del SIT no están completamente establecidos, se identifica un gen autosómico recesivo en el cromosoma 14 , así como patrones genéticos asociados, entre estos, mutaciones en CCDC11, DNAH11, TGF- $\beta$, ZIC3, INVS, NPHP3, CEP290, PK2D, NBCCS y PTCH1 los cuales están relacionados con la lateralidad anatómica, la señalización nodal y las vías de señalización como la de Hedgehog, que tiene un papel relevante en el desarrollo embrionario. En consecuencia, una alteración en esta vía provoca defectos congénitos y por otra parte, cáncer. Con base en lo anterior, los casos descritos en esta revisión podrían estar relacionados con algunas de estas mutaciones; sin embargo, no se realizó el estudio genético pertinente para determinar la presencia o no de estas, hecho que constituye una limitante de este trabajo.

Como se mencionó previamente, las variaciones genéticas también están asociadas con defectos congénitos y cáncer, denotando una prevalencia significativa de malignidades, principalmente gastrointestinales, lo cual fue pertinente para el diagnóstico diferencial del cuadro clínico de las pacientes, utilizando imágenes diagnósticas para excluir esta posibilidad.

En cuanto a malformaciones congénitas, en esta entidad se manifiestan del 5 al 10\%, describiendo una frecuencia relativamente elevada; la tetralogía de Fallot y la transposición de grandes vasos corregida son las asociaciones mejor descritas, además del síndrome de Kartagener. Aunque los casos presentados no evidenciaron sintomatología que pudiera sugerir alguna de estas entidades, sería pertinente efectuar exámenes complementarios para descartar alguna de las dos últimas patologías y sus complicaciones, teniendo en cuenta que en su grupo etáreo no es posible presentar tetralogía de Fallot ya que debe ser corregida una vez se identifica en neonatos ${ }^{41}$.

Para definir el diagnóstico de SIT en las pacientes de los casos expuestos, surgieron dudas acerca del dolor abdominal, debido a que en ambos se evidenciaba un examen físico dudoso, según la presentación anormal de los signos patológicos; por tanto, este síntoma se utilizó para llegar al diagnóstico definitivo. La ultrasonografía abdominal se empleó para determinar hallazgos característicos de apendicitis aguda, que ocupaba el primer lugar en la lista de diagnósticos diferenciales; sin embargo, esta imagen diagnóstica no concluyó la sospecha, solo identificó como hallazgo incidental SIT sin ningún otro hallazgo significativo; este fue confirmado mediante TAC, que cuenta con sensibilidad y especificidad del 99\% para identificar esta patología.
La mayoría de estos pacientes tienen una vida sana y su pronóstico está directamente relacionado con la patología asociada que desarrollen, ya sea congénita o adquirida.

El abordaje quirúrgico, además de otras intervenciones, es vital y depende del diagnóstico oportuno de esta variación y sus comorbilidades con el riesgo que implica, ya que debe modificarse la técnica quirúrgica por la imagen en espejo de las vísceras.

En la literatura se encuentran descripciones detalladas de intervenciones en pacientes con situs y sus variaciones, en las que se hace énfasis en la precaución requerida para llevarlas a cabo. Finalmente, la laparoscopia diagnóstica es una herramienta útil en intervenciones en SIT para patologías pélvico-abdominales.

\section{Conclusiones}

El SIT es una variación anatómica sin sintomatología específica, que lo convierte en hallazgo incidental en la práctica clínica. Su reconocimiento tiene gran relevancia en el diagnóstico de patologías toraco-abdominales y su correcto abordaje; además, constituye un tipo de donante con contraindicaciones relativas.

Por tratarse de una patología congénita y un hallazgo incidental, no es posible establecer una edad promedio en la cual sea diagnosticada la enfermedad, como ocurrió en los casos expuestos: mujeres en edad fértil que consultaron por dolor abdominal o síntomas ginecológicos, lo cual las hace más proclives a requerir de una imagen abdominal y por ende a una mayor probabilidad de obtenerla.

No existe una relación directa establecida entre la genética y la aparición de SIT, de ahí que es posible pensar que sea una patología con componente tanto genético como epigenético. La investigación al respecto contiene diversas hipótesis que merecen ser estudiadas.

De igual forma, se precisan estudios de cohorte para el seguimiento de pacientes con SIT con el objetivo de esclarecer la asociación específica entre alteraciones genéticas, patologías y esta variación anatómica. De otro lado, las ayudas imagenológicas más utilizadas son la radiografía de tórax, el electrocardiograma, la ultrasonografía, la laparoscopia y la TAC; esta última es la mejor forma de confirmarlo y clasificarlo ya que cuenta con sensibilidad y especificidad del $99 \%$. La ayuda quirúrgica más utilizada y documentada en la literatura no solo para el diagnóstico sino en intervenciones en SIT, es la laparoscopia exploratoria. Se resalta la importancia de la ultrasonografía en el diagnóstico prenatal del SIT para la detección temprana de malformaciones congénitas.

\section{Responsabilidades éticas}

Protección de personas y animales. Los autores declaran que para esta investigación no se han realizado experimentos en seres humanos ni en animales.

Confidencialidad de los datos. Los autores declaran que en este artículo no aparecen datos de pacientes.

Derecho a la privacidad y consentimiento informado. Los autores declaran que en este artículo no aparecen datos de pacientes. 


\section{Conflicto de intereses}

Los autores del presente trabajo declaran no tener conflicto de intereses, ni haber recibido prebendas o ayuda económica. Este documento pretende ser una contribución al conocimiento científico.

\section{Bibliografía}

1. Akbulut S, Caliskan A, Ekin A, Yagmur Y. Left-sided acute appendicitis with situs inversus totalis: review of 63 published cases and report of two cases. J Gastrointest Surg. 2010;14:1422-8.

2. Herrera-Moncada IC, Zuluaga-Restrepo JD, Meza M. Apendicitis aguda en situs inversus totalis: reporte de un caso. Rev CES Med. 2012;26:59-64.

3. Khiangte E, Newme I, Patowary K, Phukan P. Single-port laparoscopic cholecystectomy in situs inversus totalis using the E.K. glove port. J Minim Access Surg. 2013;9:180-2.

4. Osorio HOU, Flores LJD, Castillo RV. Situs inversus totalis y cardiopatía congénita: diagnóstico casual en un lactante con neumonía. CIMEL Cienc e Investig Médica Estud Latinoam. Federación Latinoamericana de Sociedades Científicas de Estudiantes de Medicina. 2010;15:85-8.

5. Dellamea MA, Sánchez LM, Cupelli Juan Correlación anatomoradiologica del situs inversus totalis. Rev Posgrado la Vla Cátedra Med. 2009;(196):16-9.

6. Paschala A, Koufakis T. Looking in the mirror: situs inversus totalis. Pan Afr Med J. 2015;20:87.

7. Rosiles-Domínguez JC, Carrillo-Sánchez D, Lever-Rosas CD, Silva-Ortiz J. Apendicetomía en paciente con situs inversus. Reporte de un caso. Rev Sanid Milit México. 2013;67:124-7.

8. Patel RB, Gupta NR, Vasava NC, Khambholja JR, Chauhan S, Desai A. Situs inversus totalis (SIT) with hepatocellular carcinoma (HCC): a rare case report and review of 12 other cases. Indian J Surg. 2013;75:424-9.

9. Iusco DR, Sacco S, Ismail I, Bonomi S, Virzì S. Three-trocar laparoscopic cholecystectomy in patient with situs viscerum inversus totalis: case report and review of the literature. G Chir. 2012;33:10-3.

10. Castro DJ, De Faria A. Case study of a sphincterotomy to remove stones from the common bile duct cholelithiasis biliary in a patient with total situs inversus. Rev Col Gastroenterol. 2013;28:139-41.

11. Valverde FMG, Ramos MJG, Martínez MM, Montesinos JMP, Rodríguez MET, Marín MR, et al. Colecistectomía laparoscópica en una paciente con situs inversus totalis. Acta Gastroenterológica Latinoam. 2010;40:264-7.

12. González RP, Lazo SL, Díaz JCQ, Rivera AG. Colecistitis aguda en paciente con situs inversus totalis. Rev Cuba Cirugía. 2011;50:339.

13. Arrabal-Polo MÁ, Jiménez-Pacheco A, Palao-Yago F. Situs inversus totalis. Imagen Diagnóstica. 2011;02:78.

14. Reddy A, Paramasivam S, Alexander N, Abhilash Ravisankar V, Thillai M. Management of a patient with situs inversus totalis with acute cholecystitis and common bile duct stones: A case report. Int J Surg Case Rep. 2014;5:821-3.

15. Mujo T, Finnegan T, Joshi J, Wilcoxen KA, Reed JC. Situs ambiguous, levocardia, right sided stomach, obstructing duodenal web, and intestinal nonrotation: a case report. J Radiol Case Rep. 2015;9:16-23.

16. Shogan PJ, Folio L. Situs inversus totalis. Mil Med. 2011;176:840-3.

17. Koiffmann CP, Wajntal A, de Souza DH, Gonzalez CH, Coates MV. Human situs determination and chromosome constitution 46,XY,ins(7;8)(q22;q12q24). Am J Med Genet. 1993;47:568-9.
18. Perles Z, Cinnamon Y, Ta-Shma A, Shaag A, Einbinder T, Rein AJJT, et al. A human laterality disorder associated with recessive CCDC11 mutation. J Med Genet. 2012;49:386-90.

19. Bartoloni L, Blouin J-L, Pan Y, Gehrig C, Maiti AK, Scamuffa N, et al. Mutations in the DNAH11 (axonemal heavy chain dynein type 11) gene cause one form of situs inversus totalis and most likely primary ciliary dyskinesia. Proc Natl Acad Sci U S A. 2002;99:10282-6.

20. Riaño DR, Junca EG, Cano Á. Situs inversus y apendicitis. Reporte de un caso y revisión de la literatura. Rev Colomb Cir. 2014;29:29-39.

21. D’Alessandro LCA, Casey B, Siu VM. Situs inversus totalis and a novel ZIC3 mutation in a family with X-linked heterotaxy. Congenit Heart Dis. 2013;8:E36-40.

22. Bataille S, Demoulin N, Devuyst O, Audrézet M-P, Dahan K, Godin $M$, et al. Association of PKD2 (polycystin 2) mutations with leftright laterality defects. Am J Kidney Dis. 2011;58:456-60.

23. Gupta M, Das D, Mittal A, Kaur H, Malhotra A. Situs inversus in a patient with nevoid basal cell carcinoma syndrome: a histogenetic relationship? J Oral Sci. 2011;53:253-6.

24. Gort Hernández M. Situs inversus totalis: presentación de un caso. Rev Ciencias Médicas Pinar del Río. 1999;14:250-5.

25. Arunabha DC, Sumit RT, Sourin B, Sabyasachi C, Subhasis M. Kartagener's syndrome: a classical case. Ethiop J Health Sci. 2014;24:363-8.

26. Lakshman VB, Revannasiddaiah S, Ganganna R. Situs inversus totalis discovered incidentally at the age of 84 years. BMJ Case Rep. 2013, http://dx.doi.org/10.1136/bcr-2013-008611:1-2

27. Carrillo Esper R, Arias Delgadillo C, Huacuja Blanco RR, García Graullera M, Carrillo Córdova CA, Carrillo Córdova DM. Situs inversus totalis. Med Int Mex. 2012;28:187-91.

28. Benhammane H, Kharmoum S, Terraz S, Berney T, Nguyen-Tang $\mathrm{T}$, Genevay M, et al. Common bile duct adenocarcinoma in a patient with situs inversus totalis: report of a rare case. BMC Res Notes. 2012;5:681.

29. Petrović M, Rabrenović V, Stamenković D, Vavić N, Kovačević $Z$, Ignjatović $L$, et al. Specificities of transplantation of kidneys procured from donors with situs inversus totalis-a case report and review of the literature. Vojnosanit Pregl. 2015;72:63-7.

30. Cajina-Gómez F. Levocardia con situs inversus abdominal. Nicaragua Pediátrica. 2015;3:44.

31. Sohns JM, Steinmetz M, Schneider H, Fasshauer M, Staab W, Kowallick JT, et al. Situs inversus totalis with congenitally corrected transposition of the great arteries: insights from cardiac MRI. Springerplus. Springer International Publishing; 2014;3(1):601.

32. de Juan Montiel J, Olagüe de Ros J, Morell Cabedo S, García Bolao I. Seguimiento del paciente con marcapasos. Disfunciones del sistema de estimulación. Efectos de indicación o programación incorrecta: síndrome de marcapasos. Rev Española Cardiol. 2007;7 Supl.G:126-44.

33. Romero-García AR, Domínguez-Pérez R de J, Fernández-Chelala FI, Santos-Hernández AM, Infanzón ER, Arias-Salazar W.;1; Marcapasos bicameral en una paciente con dextrocardia con situs inversus totalis. Rev Iberoam Arritmología. 2013; 4(1):85-91.

34. González de Dios J, Moya Benavent M, Sirvent Mayor MC, Prieto Cueto JJ, Herranz Sanchez Y, Juste Ruiz M, et al. Síndrome de Kartagener: Una infrecuente causa de distrés respiratorio neonatal. An Españoles Pediatría. 1996;45:417-20.

35. Paublo MM, Bustos VJC, Ramírez HP. Diagnostico prenatal de situs inversus totalis. Rev Chil Obstet Ginecol. 2002;67:494-7.

36. Israelit S, Brook OR, Nira B-R, Guralnik L, Hershko D. Leftsided perforated acute appendicitis in an adult with midgut malrotation: the role of computed tomography. Emerg Radiol. 2009;16:217-8.

37. Kim YW, Ryu H, Kim DS, Kim IY. Double primary malignancies associated with colon cancer in patients with situs inversus totalis: two case reports. World J Surg Oncol. 2011;9:109. 
38. Juncos CM, Ros FMA, Maravall LI M, Álvarez-Pitti J. Situs inversus totalis - 2 case reports. Rev Chil Pediatr. 2014;85:344-50.

39. Yamamoto F, Yamamoto M. Scanning copy number and gene expression on the 18q21-qter chromosomal region by the systematic multiplex PCR and reverse transcription-PCR methods. Electrophoresis. 2007;28:1882-95.
40. Haruki T, Maeta Y, Nakamura S, Sawata T, Shimizu T, Kishi K, et al. Advanced cancer with situs inversus totalis associated with KIF3 complex deficiency: report of two cases. Surg Today. 2010;40:162-6.

41. Alva Espinosa C. Tetralogía de Fallot: Actualización del diagnóstico y tratamiento. Rev Mex Cardiol. 2013;24:87-93. 